\title{
Pengembangan Aplikasi Pengelolaan Persediaan Bahan pada Usaha Kecil Menengah Pakaian Jadi
}

\author{
http://dx.doi.org/10.28932/jutisi.v7i3.4125 \\ Riwayat Artikel
}

Received: 26 Oktober 2021 | Final Revision: 20 November 2021 | Accepted: 24 November 2021

\author{
Antonius Susanto $^{\# 1}$, Cecilia Esti Nugraheni ${ }^{\# \bowtie 2}$, Maria Widyarini ${ }^{* 3}$ \\ \#Program studi Teknik Informatika, Universitas Katolik Parahyangan \\ Jln. Ciumbuleuit 94 Bandung 40141 \\ 17316055.studenteunpar.ac.id \\ ${ }^{2}$ cheni@unpar.ac.id \\ *Program studi Ilmu Administrasi Bisnis, Universitas Katolik Parahyangan \\ Jln. Ciumbuleuit 94 Bandung 40141 \\ ${ }^{3}$ widya@unpar.ac.id
}

\begin{abstract}
Clothing is one of the basic or primary needs. With the influence of clothing fashion that continues to grow, many Small and Medium Enterprises (SMEs) have sprung up engaged in the clothing sector. SMEs are one of the driving forces of the Indonesian economy. SMEs engaged in the clothing sector are businesses that produce apparel. The materials used in the manufacture of clothing also vary, so that inventory management and material requirements planning are essential processes in the manufacture of clothing. In this study, a simple mobile application was developed that can be used for material inventory management for SMEs. The primary function of this application is to record materials (inventory) and plan production needs using the Reorder Point (ROP) method. The Reorder Point (ROP) method is an order limit point helpful in knowing when a company holds an order. Program development using Android Studio IDE with Flutter framework and Dart programming language. The results of functional testing on this application are $90 \%$ achieved following the expected results. The user acceptance test concludes that this application has the potential to facilitate SMEs in managing the inventory of material.
\end{abstract}

Keywords — clothing; mobile application; SMEs; stock management.

\section{PENDAHULUAN}

Pakaian termasuk salah satu kebutuhan pokok atau primer yang selalu dicari masyarakat. Dengan adanya pengaruh fashion pakaian yang terus berkembang maka banyak bermunculan Usaha Kecil Menengah (UKM) yang bergerak pada bidang pakaian. UKM adalah salah satu motor penggerak perekonomian Indonesia. UKM menyumbang sekitar $60 \%$ dari Product Domestic Bruto (PDB) dan juga memberikan kesempatan kerja pada banyak masyarakat. UKM yang bergerak pada bagian pakaian adalah usaha yang memproduksi pakaian jadi. Secara lebih spesifik UKM pakaian jadi memproduksi pakaian seperti kaos, jaket, kemeja, dan celana. Dalam mengelola UKM yang bergerak pada bidang pakaian, terdapat beberapa proses penting seperti menerima pesanan, pemasaran, produksi, penyimpanan dan pengendalian bahan.

Bahan yang digunakan dalam pembuatan pakaian juga bervariatif, sehingga pengelolaan persediaan dan perencanaan kebutuhan bahan merupakan proses penting dalam pembuatan pakaian. Agar proses produksi berjalan dengan lancar, ketersediaan bahan baku harus terjamin. Namun persediaan bahan baku yang berlebihan akan menimbulkan permasalahan dalam hal tempat penyimpanan, perawatan, dan kerugian dari sisi keuangan. Dari pengamatan awal, pengelolaan persediaan oleh para pelaku UKM masih banyak yang dilakukan secara manual dengan membuat catatan di atas kertas dalam sebuah buku harian (jurnal). Sebagian bahkan hanya mengandalkan ingatan. Situasi ini tentu berpotensi membawa masalah dalam proses produksi.

Banyak penelitian yang mengkaji permasalahan pengelolaan persediaan dan penyimpanan bahan. Sebagian besar menggunakan pendekatan metode ROP (Reorder Point), SS (Safety Stock), dan EOQ (Economically Order Quantity) [1]-[7]. Banyak penelitian mengembangkan perangkat lunak (aplikasi atau sistem informasi) dengan ketiga pendekatan tersebut untuk berbagai domain permasalahan [8]-[15] baik berbasis web maupun aplikasi bergerak (mobile application). 
Penelitian ini bertujuan untuk mengembangkan sebuah program komputer sederhana yang dapat digunakan untuk pengelolaan persediaan bahan bagi para pelaku UKM yang bergerak di produksi pakaian jadi, khususnya kaos polos. Fungsi utama dari program adalah untuk pencatatan bahan (inventory) sekaligus untuk perencanaan kebutuhan produksi (planning). Program yang dikembangkan berbentuk aplikasi bergerak. Bentuk aplikasi ini dipilih dengan pertimbangan kemudahan dalam pengoperasian. Dengan aplikasi yang tertanam pada perangkat bergerak, memungkinkan para pelaku UKM untuk mengakses aplikasi ini dimana saja. Rumusan masalah yang akan dijawab pada penelitian ini adalah bagaimana pengelolaan persediaan bahan yang biasa dipraktekkan, metode pengelolaan dan perencanaan kebutuhan apa yang sesuai, dan fitur-fitur tambahan apa yang diperlukan oleh para pelaku UKM.

Dalam pengembangan aplikasi akan digunakan platform android studio. Android studio adalah Lingkungan Pengembangan Terpadu (Integrated Development Environment/IDE) resmi untuk pengembangan aplikasi android. Framework yang digunakan adalah Flutter. Flutter adalah sebuah SDK (Software Development Kit) buatan Google yang berfungsi untuk membuat aplikasi bergerak menggunakan bahasa pemrograman Dart. Dart merupakan bahasa bahasa pemrograman yang dirancang untuk pengembangan klien, seperti untuk web dan aplikasi bergerak.

\section{METODE PENELITIAN}

Penelitian dilaksanakan dengan mengikuti serangkaian tahapan seperti yang ditunjukkan pada Gambar 1. Secara umum kegiatan penelitian mencakup studi literatur, pengumpulan data, pengembangan perangkat lunak, dan pengambilan kesimpulan. Pengembangan perangkat lunak terdiri atas analisis kebutuhan, perancangan, implementasi dan pengujian. Studi literatur difokuskan pada pencarian pendekatan untuk pengelolaan persediaan. Pengumpulan data dilaksanakan dalam bentuk wawancara dengan beberapa pelaku UKM pakaian jadi di Bandung. Pengumpulan data ini bertujuan untuk mengetahui bagaimana praktek pengelolaan bahan di masing-masing UKM. Hasil dari studi literatur dan wawancara ini kemudian dianalisis lebih lanjut sehingga dapat ditentukan bagaimana pendekatan pengelolaan persediaan bahan yang akan diimplementasikan kedalam perangkat lunak aplikasi.

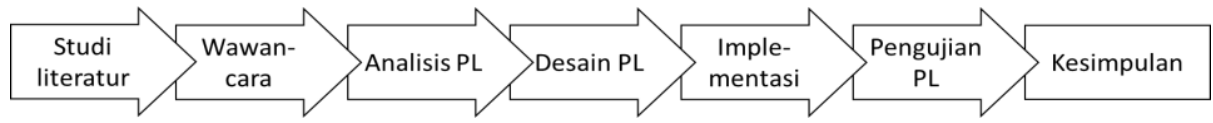

Gambar 1.Tahapan penelitian.

\section{A. Studi literatur}

Bagi pelaku UKM pakaian jadi, dan produsen barang-barang secara umum, ketersediaan bahan berpengaruh dalam kelancaran proses produksi. Ketidaksiapan bahan produksi pada saat yang diperlukan akan menghambat proses produksi secara keseluruhan yang akan berdampak pada keterlambatan penyelesaian pekerjaan. Dampak lainnya adalah keterlambatan proses penyerahan (delivery) kepada pelanggan. Hal ini lebih jauh lagi dapat berpengaruh pada turunnya kepuasan pelanggan bahkan hilangnya kepercayaan pelanggan. Situasi ini tentu sangat tidak diharapkan. Untuk mencegah terjadinya situasi tersebut, maka persediaan barang harus dikelola dengan baik. Kondisi ideal yaitu barang selalu tersedia di gudang seringkali sulit untuk dipenuhi. Penyimpanan barang yang berlebihan selain memakan tempat, juga memerlukan biaya pemeliharaan yang tidak kecil. Oleh karena itu persediaan bahan harus dikelola dengan sebaik-baiknya.

Dari literatur diperoleh beberapa metode yang biasa digunakan dalam pengelolaan persediaan bahan. Tiga di antaranya adalah Reorder Point (ROP), Safety Stock (SS), dan Economic Order Quantity (EOQ). ROP atau titik pemesanan ulang adalah metode yang digunakan untuk menentukan kapan pemesanan harus dilakukan. SS adalah persediaan minimal yang ada dalam gudang atau tempat penyimpanan agar tidak terjadi kekurangan bahan yang disebabkan ketidakpastian dari supplier atau permintaan barang di pasar. EOQ digunakan untuk menentukan kuantitas bahan yang harus dipesan yang paling optimal dilihat dari sisi biaya dan waktu. Hubungan antara ROP, SS, dan EOQ dapat dijelaskan dengan menggunakan Gambar 2.

Pada prinsipnya, sebuah perusahaan harus menjamin bahwa bahan produksi selalu tersedia sehingga tidak mengganggu proses produksi. Ketersediaan bahan harus dipantau secara terus menerus atau secara periodik. Misal bahan yang tersedia pada saat awal adalah A (stok = A). Seiring dengan proses produksi, ketersediaan bahan akan berkurang. Banyaknya bahan akan berbanding terbalik dengan waktu. Jika diasumsikan pemakaian bahan konstan setiap waktunya, misal s, maka grafiknya akan berupa garis lurus dengan gradien 1/s. Garis ini akan memotong sumbu x pada titik D yang menyatakan kondisi dimana bahan habis (stok = 0). Kondisi dimana persediaan bahan habis harus dihindari. Untuk itu harus dilakukan pengadaan/pembelian sebelum stok kosong. Bahkan, jika perusahaan tersebut telah menetapkan SS, maka pengadaan harus dilakukan sebelum SS tercapai $($ stok $=$ C). 


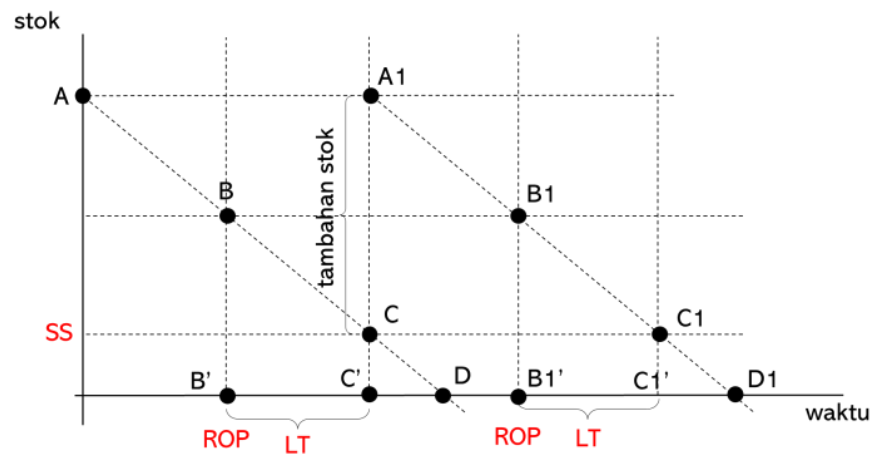

Gambar 2. Reorder Point.

Pada prakteknya, pengadaan bahan tidak bisa dilakukan secara langsung. Seringkali bahan baru dapat diterima beberapa saat setelah pembelian atau pemesanan dilakukan. Waktu yang diperlukan untuk menunggu barang sejak pemesanan dilakukan sampai barang diterima disebut dengan lead time (LT). Jika LT ini diketahui, maka dapat ditentukan titik B yang merupakan titik dimana pemesanan bahan harus dilakukan atau ROP. Titik B' yang merupakan proyeksi titik B ke sumbu $x$ menyatakan waktu kapan pemesanan ulang harus dilakukan. Untuk menentukan banyaknya (kuantitas) bahan yang harus dipesan (A1-C), dapat digunakan EOQ. Dengan asumsi pemakaian bahan tetap maka pola ini akan berulang dan ROP yang berikutnya dapat ditentukan.

Rumus ROP dapat dituliskan sebagai persamaan (1) berikut [16]:

dimana

$$
\mathrm{ROP}=\mathrm{SS}+\mathrm{SLT}
$$

- $\quad$ ROP : Reorder point (dalam satuan unit bahan)

- SS : Safety stock (dalam satuan unit bahan)

- $\quad$ s : pemakaian bahan per periode (dalam satuan unit bahan / satuan waktu)

- $\quad$ LT : Lead Time (dalam satuan waktu)

Rumus EOQ diberikan pada persamaan (2) berikut [17]:

dimana

$$
\mathrm{EOQ}=\sqrt{\frac{2 \mathrm{Ss}}{\mathrm{H}}}
$$

- EOQ : Economic order quantity (dalam satuan unit bahan)

- $\mathrm{S} \quad$ : biaya pemesanan per unit (dalam satuan unit harga)

- $\quad$ s : pemakaian bahan per periode (dalam satuan unit bahan / satuan waktu)

- $\mathrm{H} \quad$ : biaya penyimpanan per unit (dalam satuan harga / satuan waktu)

\section{B. Wawancara}

Dalam tahap analisis kebutuhan perangkat lunak dilakukan wawancara secara daring kepada beberapa pelaku UKM pakaian jadi di Bandung dan sekitarnya. Pertanyaan yang diajukan dalam wawancara tersebut mencakup sejarah singkat, pesanan minimal, proses produksi, pengelolaan/pencatatan persediaan bahan, masalah dan solusi dalam pengadaan bahan baku, kesediaan nama disebutkan dan kesediaan menjadi penguji perangkat lunak.

Kesimpulan yang dapat diambil dari hasil wawancara adalah sbb.:

1. Pelaku UKM tidak menggunakan metode manajemen dalam pengendalian bahan maupun perencanaan bahan.

2. Perhitungan perencanaan bahan menggunakan perhitungan tradisional.

3. Pelaku UKM hanya menggunakan aplikasi Excel.

4. Pelaku UKM sering mengalami kekurangan bahan baku atau kelebihan bahan baku.

5. Tidak semua UKM memperhatikan aspek tempat penyimpanan bahan (gudang).

6. Tidak semua UKM memperhatikan Lead Time. 


\section{Analisis Fungsional}

Dari hasil studi literatur dan wawancara dan analisis lebih lanjut, disimpulkan bahwa kebutuhan utama yang harus didukung oleh aplikasi adalah pencatatan persediaan bahan, pencatatan pengadaan atau pembelian bahan, pencatatan pemakaian, dan perencanaan pengadaan bahan. Selain itu perlu ditambahkan fitur tambahan yang berguna bagi pengguna yaitu pencatatan aktivitas (kalender), pengaturan informasi pengguna, dan bantuan penggunaan aplikasi.

Gambar 3 menunjukkan interaksi antara pengguna dengan aplikasi. Use case Diagram ini juga sekaligus mendefinisikan fungsionalitas dari aplikasi. Tampak pada gambar tersebut, terdapat tujuh buah interaksi yang dapat terjadi antara pengguna dan aplikasi, yaitu mengelola penyimpanan, mengelola perencanaan, mengelola pembelian, mengelola pemakaian, mengelola kalender, pengaturan, dan mendapatkan bantuan. Untuk setiap fungsi pengelolaan, pengguna dapat melakukan aktivitas tambah, hapus dan ubah (CRUD) terhadap data yang sudah tersimpan sebelumnya.

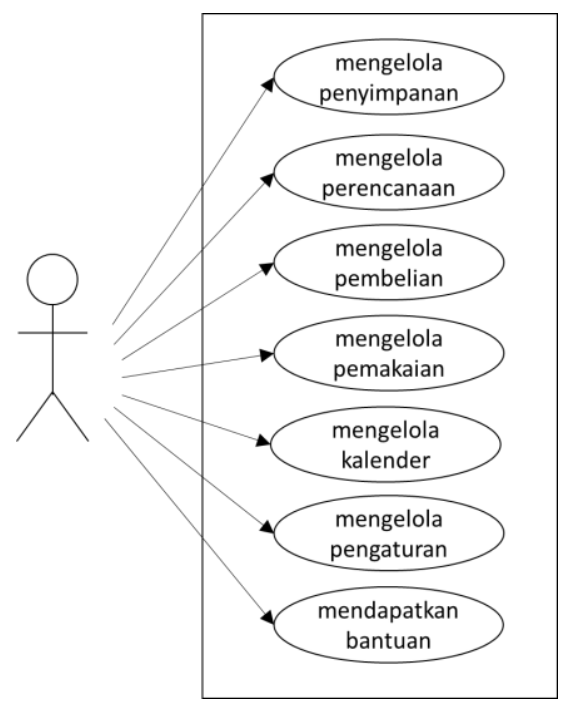

Gambar 3. Use Case Diagram.

Use case diagram dilengkapi dengan skenario dan dirinci dengan menggunakan diagram aktivitas. Dua diagram pada Gambar 4 adalah diagram aktivitas untuk menu utama dan proses insert dari Use Case Pembelian.


Gambar 4. Diagram aktivitas untuk Menu Utama dan Insert Pembelian. 
Dua diagram pada Gambar 5 adalah diagram aktivitas proses delete dan update dari Use Case Pembelian.
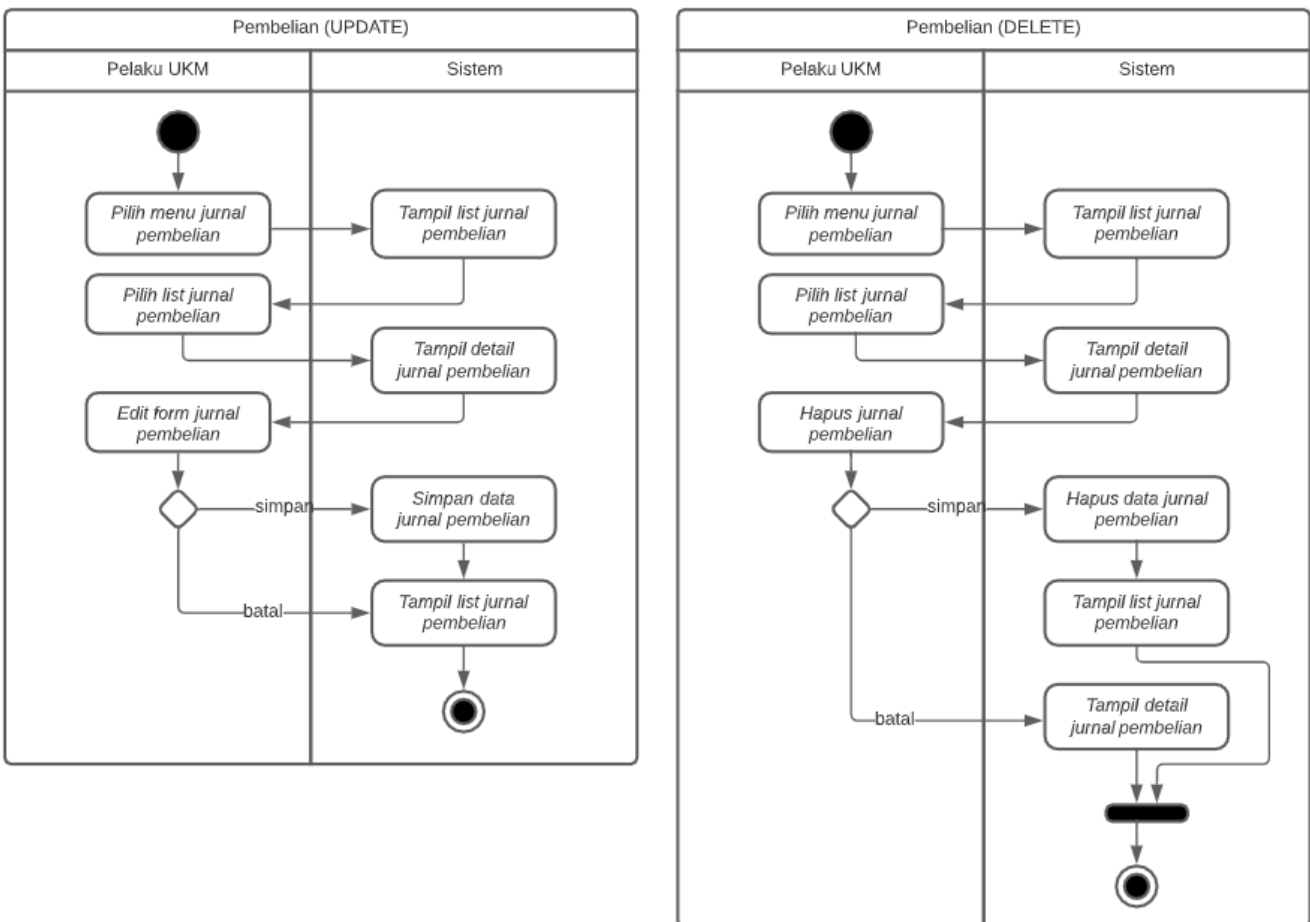

Gambar 5. Diagram aktivitas untuk Update dan Delete Pembelian.

Gambar 6 memperlihatkan proses insert dan update perencanaan bahan. Pada aktivitas insert perencanaan bahan dilakukan perhitungan ROP dan EOQ.
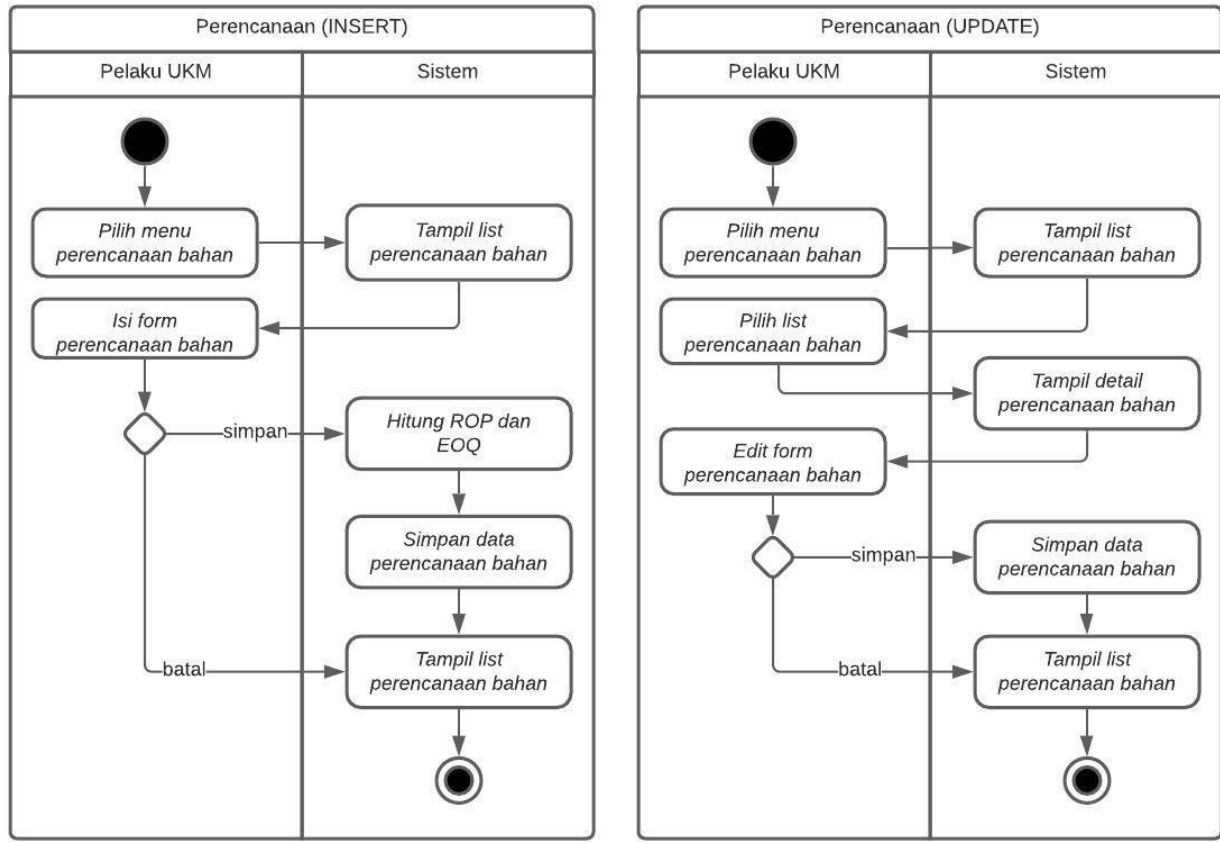

Gambar 6. Diagram aktivitas untuk Insert dan Update Perencanaan. 


\section{Analisis Basis Data}

Dari fungsionalitas yang sudah ditetapkan, ditentukan entitas apa saja yang harus ada di aplikasi dan keterkaitan antar entitas tersebut. Gambar 7 menunjukkan entitas utama dan keterhubungan antar entitas tersebut. Ada empat entitas utama yaitu BAHAN, PEMBELIAN, PEMAKAIAN, dan PERENCANAAN. Salah satu atribut dari entitas BAHAN adalah jumlah yang menyatakan banyaknya persediaan bahan (stok) sehingga entitas ini dapat juga disebut sebagai entitas PERSEDIAAN. Entitas BAHAN berelasi dengan entitas PERENCANAAN dengan hubungan one to one dan berelasi dengan dua entitas yang lain dengan hubungan one to many. Atribut bsimpan pada entitas BAHAN menyatakan biaya penyimpanan bahan.

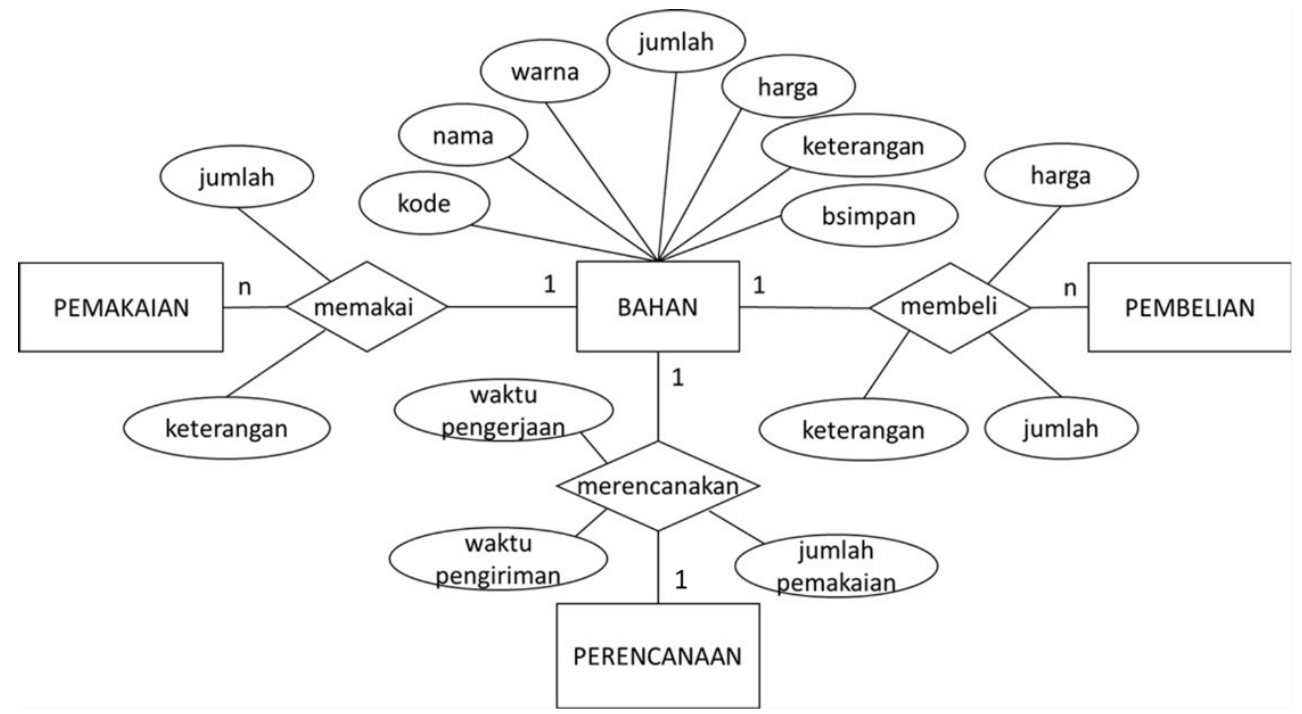

Gambar 7. Entity Relationship Diagram.

\section{E. Perancangan Antarmuka}

Gambar 8 dan Gambar 9 menampilkan contoh rancangan antarmuka dari aplikasi. Setiap gambar terdiri atas empat gambar contoh rancangan antarmuka. Selain tujuh menu sesuai dengan fungsionalitas yang sudah ditetapkan, ditambahkan satu menu yaitu Halaman Utama seperti yang ditunjukkan pada Gambar 8(a).

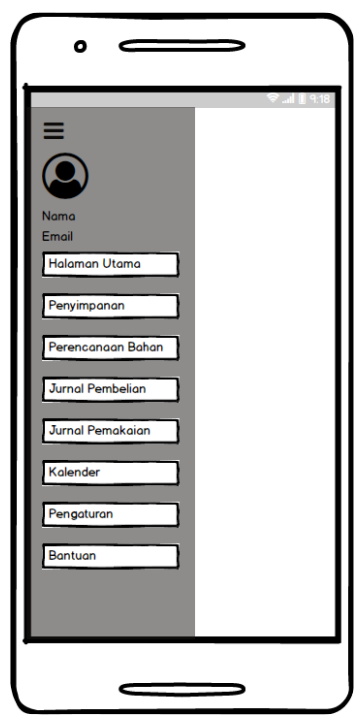

(a)

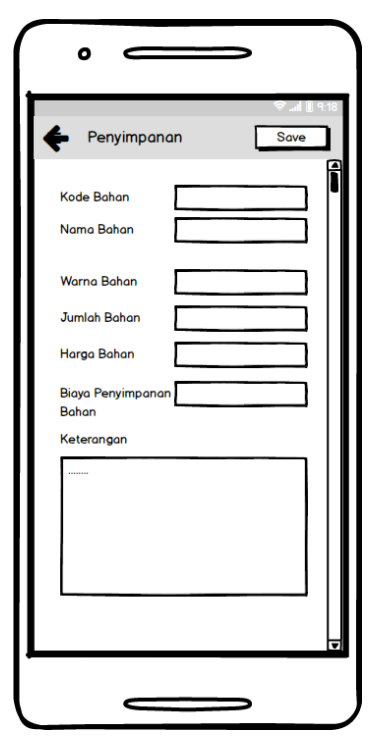

(b)

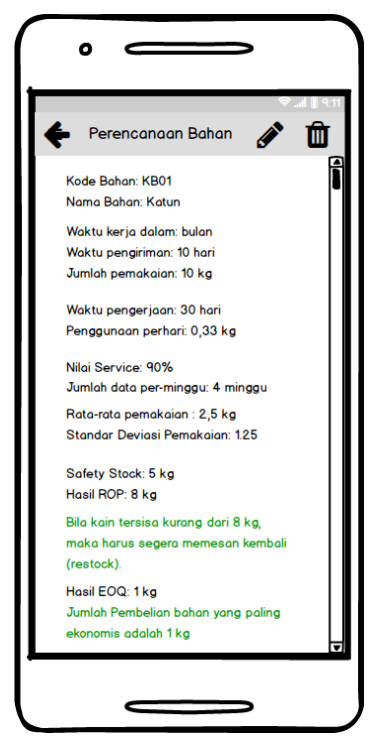

(c)

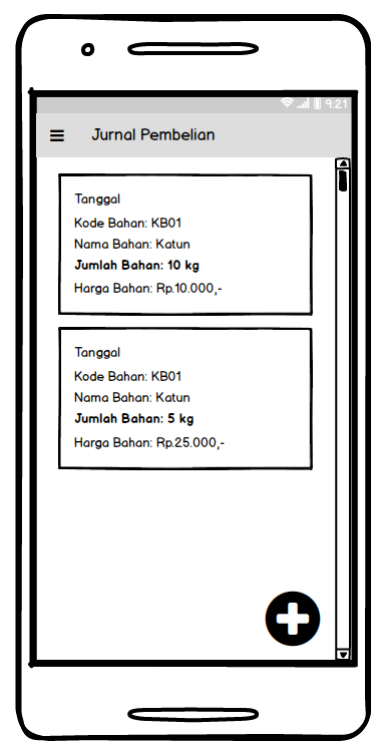

(d)

Gambar 8. Contoh rancangan antarmuka (a) Menu Utama, (b) Penyimpanan, (c) Perencanaan Bahan, dan (d) Jurnal Pembelian. 




(a)

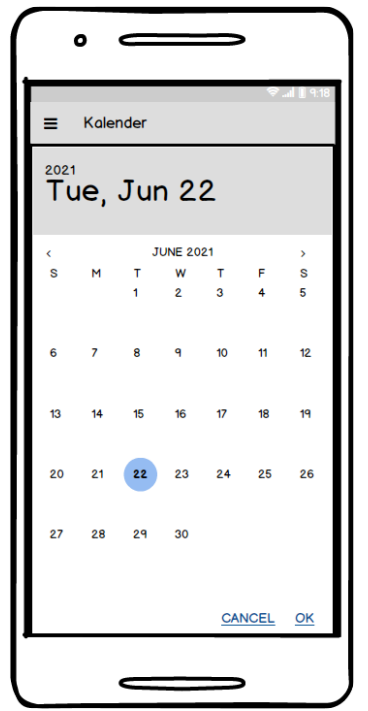

(b)

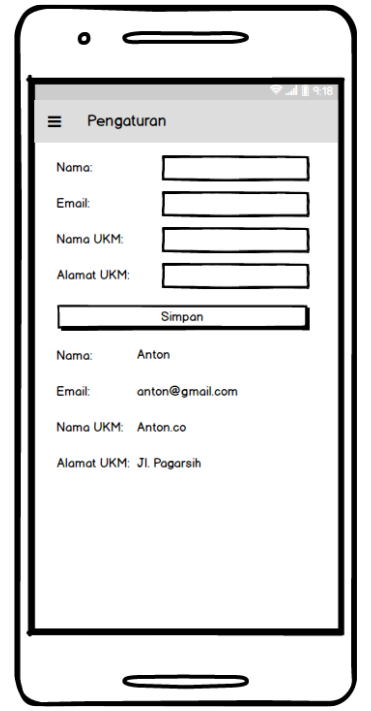

(c)

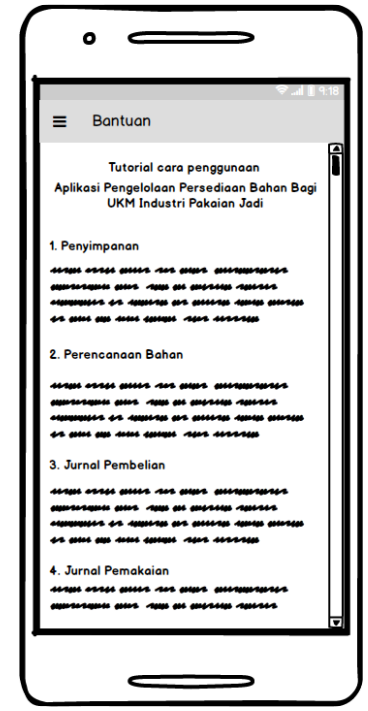

(d)

Gambar 9. Contoh rancangan antarmuka (a) Jurnal Pemakaian, (b) Kalender, (c) Pengaturan dan (d) Bantuan.

\section{HASIL DAN PEMBAHASAN}

\section{A. Implementasi}

Gambar 10 dan Gambar 11 menampilkan beberapa contoh tampilan hasil implementasi perangkat lunak aplikasi berdasarkan hasil tahapan analisis dan perancangan.

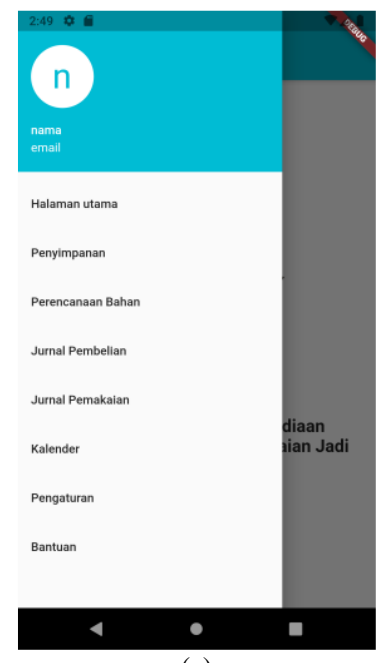

(a)

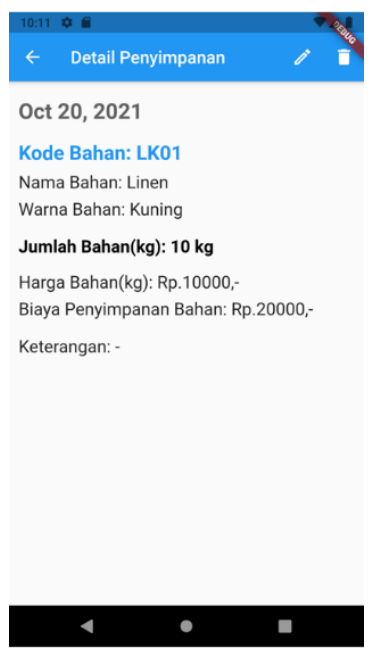

(b)

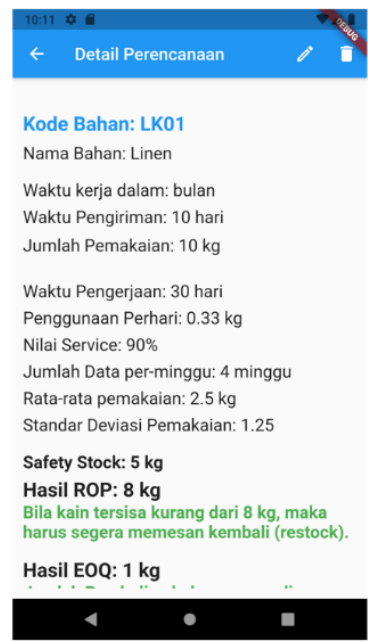

(c)

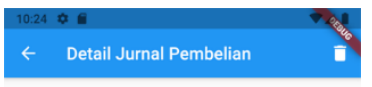

Oct 20, 2021

Kode Bahan: LK01

Nama Bahan: Linen

Warna Bahan: Kuning

Jumlah Bahan(kg): 10 kg

Harga Bahan(kg): Rp. 10000,

Keterangan: -

Gambar 10. Contoh implementasi antarmuka (a) Menu Utama, (b) Penyimpanan, (c) Perencanaan Bahan, dan (d) Jurnal Pembelian. 


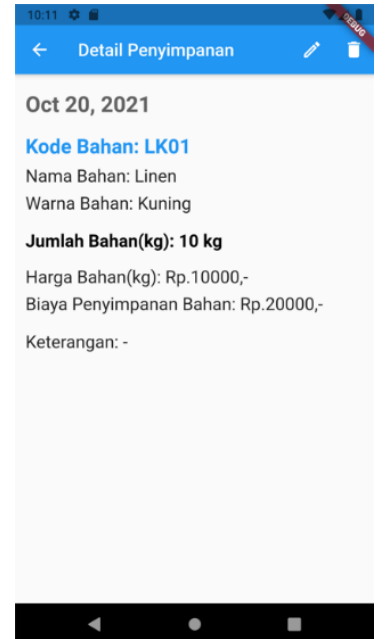

(e)

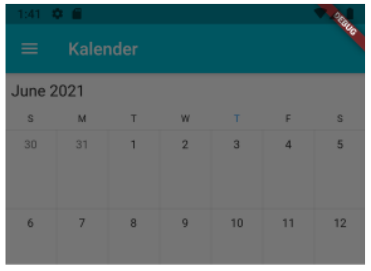

June 2021
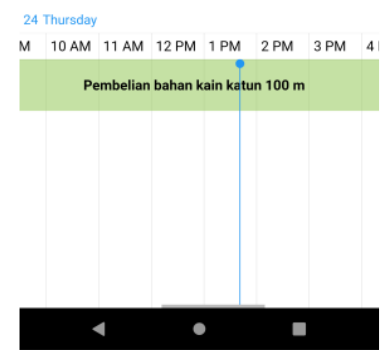

(f)

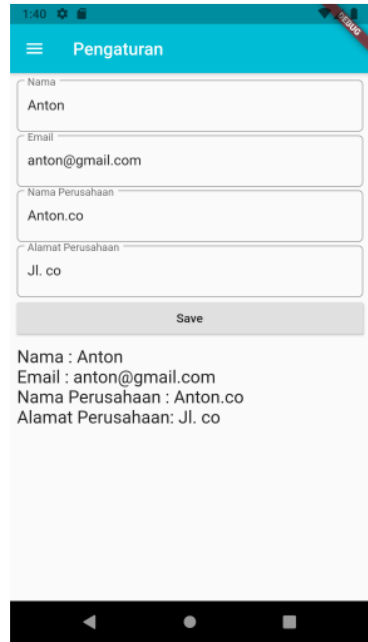

(g)

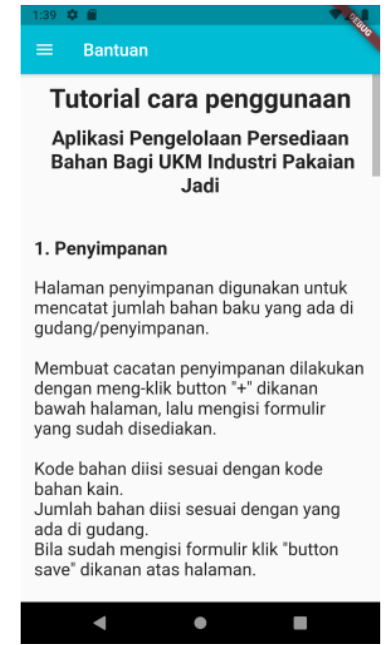

(h)

Gambar 11. Contoh implementasi antarmuka (a) Jurnal Pemakaian, (b) Kalender, (c) Pengaturan dan (d) Bantuan

\section{B. Functional Testing}

Functional testing atau pengujian fungsional bertujuan untuk memastikan perangkat lunak berjalan sesuai fungsi dan tidak ada $b u g$. Pengujian dilakukan sebelum aplikasi diberikan kepada calon pengguna yaitu pelaku UKM untuk dilakukan User Acceptance Testing (pengujian penerimaan pengguna). Hasil pengujian fungsional diberikan pada Tabel 1. Tampak pada Tabel 1 bahwa aplikasi yang dikembangkan telah memenuhi hampir seluruh aspek yang diharapkan. Pengujian ini juga telah menerapkan test cases yang meliputi semua skenario yang mungkin. Dari tujuh kelompok pengujian, hanya satu yang tidak mencapai $100 \%$, yaitu bagian pengaturan. Fitur pengaturan mencapai tingkat keberhasilan $80 \%$ dikarenakan ada sebagian data yang tidak berhasil tersimpan. Secara rata-rata hasil Functional Testing adalah 97,14\%.

TABEL 1

FunCTIONAL TESTING

\begin{tabular}{|c|c|c|c|c|}
\hline No & Fitur & Data & Hasil yang diharapkan & $\begin{array}{c}\text { Tingkat } \\
\text { keberhasilan }\end{array}$ \\
\hline \multirow[t]{7}{*}{1} & \multirow[t]{7}{*}{ Penyimpanan bahan } & Kode Bahan & \multirow{7}{*}{$\begin{array}{l}\text { Pelaku UKM dapat menyimpan } \\
\text { data penyimpanan bahan. }\end{array}$} & \multirow[t]{7}{*}{$100 \%$} \\
\hline & & Nama Bahan & & \\
\hline & & Warna Bahan & & \\
\hline & & Jumlah Penyimpanan & & \\
\hline & & Harga bahan & & \\
\hline & & Biaya penyimpanan & & \\
\hline & & Keterangan & & \\
\hline \multirow[t]{5}{*}{2} & \multirow[t]{5}{*}{ Perencanaan bahan } & Kode Bahan & \multirow{5}{*}{$\begin{array}{l}\text { Pelaku UKM mendapatkan hasil } \\
\text { ROP secara otomatis dan dapat } \\
\text { menyimpan data perencanaan } \\
\text { bahan. }\end{array}$} & \multirow[t]{5}{*}{$100 \%$} \\
\hline & & Nama Bahan & & \\
\hline & & Waktu Kerja & & \\
\hline & & Waktu Pengiriman & & \\
\hline & & Jumlah Pemakaian & & \\
\hline \multirow[t]{6}{*}{3} & \multirow[t]{6}{*}{ Jumlah pembelian } & Kode Bahan & \multirow{6}{*}{$\begin{array}{l}\text { Pelaku UKM dapat menyimpan } \\
\text { data pemakaian bahan. Jumlah } \\
\text { bahan pada penyimpanan } \\
\text { otomatis bertambah. }\end{array}$} & \multirow[t]{6}{*}{$100 \%$} \\
\hline & & Nama Bahan & & \\
\hline & & Warna Bahan & & \\
\hline & & Jumlah Pembelian & & \\
\hline & & Harga bahan & & \\
\hline & & Keterangan & & \\
\hline \multirow[t]{3}{*}{4} & \multirow[t]{3}{*}{ Jumlah pemakaian } & Kode Bahan & \multirow{3}{*}{$\begin{array}{l}\text { Pelaku UKM dapat menyimpan } \\
\text { data pemakaian bahan. Jumlah } \\
\text { bahan pada penyimpanan } \\
\text { berkurang otomatis. }\end{array}$} & \multirow[t]{3}{*}{$100 \%$} \\
\hline & & Nama Bahan & & \\
\hline & & Warna Bahan & & \\
\hline
\end{tabular}


TABEL 1 (LANJUTAN)

FunCtionAl TESTING

\begin{tabular}{|c|c|c|c|c|}
\hline No & Fitur & Data & Hasil yang diharapkan & $\begin{array}{c}\text { Tingkat } \\
\text { keberhasilan }\end{array}$ \\
\hline & & Jumlah Pemakaian & & \\
\hline & & Keterangan & & \\
\hline \multirow[t]{5}{*}{5} & \multirow[t]{5}{*}{ Kalender } & Judul Catatan & \multirow{5}{*}{$\begin{array}{l}\text { Pelaku UKM dapat menyimpan } \\
\text { data catatan kalender. }\end{array}$} & \multirow[t]{5}{*}{$100 \%$} \\
\hline & & Tanggal Awal & & \\
\hline & & Jam Awal & & \\
\hline & & Tanggal Akhir & & \\
\hline & & Jam Akhir & & \\
\hline \multirow[t]{4}{*}{6} & \multirow[t]{4}{*}{ Pengaturan } & Nama & \multirow{4}{*}{$\begin{array}{l}\text { Pelaku UKM dapat menyimpan } \\
\text { data pengaturan. }\end{array}$} & \multirow[t]{4}{*}{$80 \%$} \\
\hline & & Email & & \\
\hline & & Nama Perusahaan & & \\
\hline & & Alamat Perusahaan & & \\
\hline 7 & Bantuan & & $\begin{array}{l}\text { Pelaku UKM dapat mengerti } \\
\text { tutorial penggunaan aplikasi. }\end{array}$ & $100 \%$ \\
\hline
\end{tabular}

\section{Pengujian Penerimaan Pengguna (User Acceptance Testing)}

Pengujian penerimaan pengguna bertujuan untuk menguji apakah aplikasi sudah sesuai dengan kebutuhan calon pengguna. Pengujian ini dilakukan dengan cara memberikan aplikasi kepada dua pelaku UKM di Bandung yaitu Once upon a time dan Konveksi Baju Bandung. Setelah melakukan pengujian aplikasi, para pelaku UKM diminta mengisi formulir pengujian yang terdiri atas delapan pertanyaan sbb.:

1. Apakah penggunaan aplikasi memudahkan dalam mengelola persediaan bahan baku?

2. Apakah tampilan aplikasi memudahkan dalam menggunakan aplikasi?

3. Apakah aplikasinya mudah untuk digunakan?

4. Apakah perhitungan perencanaan bahan atau titik pemesanan kembali sesuai dengan yang sudah dipraktekkan?

5. Apakah tombol bantuan memudahkan dalam menggunakan aplikasi?

6. Manfaat apa yang didapatkan setelah menggunakan aplikasi?

7. Apakah ada kendala dalam menggunakan aplikasi?

8. Masukan atau saran untuk aplikasi.

Jawaban dari kedua pelaku UKM diberikan pada Tabel 2.

TABEL 2

USER ACCEPTANCE TESTING

\begin{tabular}{|c|c|c|}
\hline Pertanyaan & Pelaku UKM 1 & Pelaku UKM 2 \\
\hline 1 & Mempermudah & Mempermudah \\
\hline 2 & Mudah digunakan & Mempermudah \\
\hline 3 & Mudah & Cukup memudahkan \\
\hline 4 & Sesuai & Tidak sesuai karena tidak cocok dengan konveksi jasa. \\
\hline 5 & Iya, mempermudah. & Memudahkan. \\
\hline 6 & Pengecekan stok kain jadi lebih, & Lebih mudah mengetahui sisa bahan. \\
\hline 7 & $\begin{array}{l}\text { Tidak bisa memasukkan jumlah } \\
\text { bahan dalam desimal. }\end{array}$ & Tidak bisa memasukkan angka desimal di jumlah bahan. \\
\hline 8 & $\begin{array}{l}\text { Untuk penyimpanan sebaiknya } \\
\text { ditampilkan warna kain. Dalam } \\
\text { jurnal pembelian dan pemakaian } \\
\text { sebaiknya tidak perlu mengisi lagi } \\
\text { nama dan warna bahan. }\end{array}$ & $\begin{array}{l}\text { Perencanaan bahan kurang sesuai untuk konveksi jasa } \\
\text { karena pengadaan bahan berdasarkan pesanan. Akan lebih } \\
\text { baik kalau digabungkan dengan aplikasi penjadwalan } \\
\text { produksi dengan salah satu fitur adalah pengingat tenggat } \\
\text { waktu dari setiap tahapan proses produksi. }\end{array}$ \\
\hline
\end{tabular}

Dari jawaban yang diberikan oleh kedua pelaku UKM, dapat disimpulkan sbb.:

1. Secara umum aplikasi mempermudah dalam pengendalian bahan dan aplikasinya mudah untuk digunakan. 
2. Perencanaan bahan dengan menggunakan metode ROP lebih sesuai untuk UKM konveksi produksi, tetapi kurang sesuai bagi UKM konveksi jasa. Pada prakteknya, pengadaan bahan oleh UKM konveksi cenderung berdasarkan pesanan pelanggan.

3. Kekurangan yang ditemukan pada aplikasi adalah pencatatan detail bahan yang harus berulang dan jumlah bahan yang harus selalu berupa bilangan bulat.

4. Saran pengembangan adalah perbaikan untuk kekurangan yang ada dan penyediaan fitur yang berkaitan dengan penjadwalan produksi

\section{SIMPULAN}

Pada penelitian ini telah berhasil dibangun Aplikasi Pengelolaan Persediaan Bahan Bagi UKM Pakaian Jadi yang berfungsi untuk pencatatan bahan dan perencanaan kebutuhan bahan dengan menggunakan pendekatan ROP dan EOQ. Pembangunan program menggunakan IDE Android Studio dengan framework Flutter dan bahasa pemrograman Dart. Aplikasi yang dibangun juga memiliki pengaturan profil pelaku UKM, bantuan, dan kalender.

Hasil Functional Testing adalah 97,14\% tercapai sesuai dengan hasil diharapkan. Hasil User Acceptance Testing mendapatkan umpan balik dari calon pengguna yaitu dua pelaku UKM dengan hasil aplikasi ini memudahkan dalam mengelola persediaan bahan bagi para pelaku UKM.

Pencatatan bahan dalam aplikasi berfungsi untuk UKM konveksi produksi dan konveksi jasa. UKM konveksi jasa melakukan produksi apabila ada pesanan dari pembeli. UKM konveksi produksi melakukan produksi pakaian secara berkala. Perhitungan kebutuhan bahan dengan metode ROP dalam aplikasi berfungsi untuk UKM konveksi produksi, tetapi tidak untuk UKM konveksi jasa karena tidak sesuai.

Untuk penelitian lebih lanjut, aplikasi dapat dikembangkan agar dapat mengakomodasi UKM konveksi jasa. Di samping itu, aplikasi akan ditambahkan fitur yang berkaitan dengan kegiatan penjadwalan proses produksi.

\section{UCAPAN TERIMA KASIH}

Ucapan terima kasih disampaikan kepada Kemendikbud Ristek yang telah memberikan pembiayaan penelitian ini dalam skema Penelitian Terapan Unggulan Perguruan Tinggi dengan nomor kontrak 065/SP2H/LT/DRPM/2021.

\section{DAFTAR PUSTAKA}

[1] R. Rohmanudin, Analisis Kebutuhan Bahan Baku Konveksi Dalam Rangka Permintaan dengan Menggunakan Metode Economic Order Quantity (EOQ) (Studi Kasus di UKM Suckseed Konveksi Tasikmalaya), Jurnal Mahasiswa Industri Galuh (JMIG) vol 1, no. 1, pp. 23-30, 2020.

[2] A. Iskandar, Analisis Manajemen Persediaan Bahan Baku pada Perusahaan Base Camp Clothing dengan Menggunakan Metode Economic Order Quantity (EOQ), Prosiding Manajemen, vol. 3, no. 2, pp. 1214-1221, 2017.

[3] L.D. Lestari, Penerapan Metode Economic Order Quantity (EOQ) untuk meminimumkan Biaya Persediaan Bahan Baku di UKM Makaroni Makarena Malang, Jurnal Valtech, vol. 1 no. 1, pp. 138-142, 2018.

[4] L. Luftfiana, dan I. Puspitosari, Analisis Manajemen Persediaan Pada Usaha Mikro, Kecil, dan Menengah (UMKM) Jazid Bastomi Batik di Purworejo, Jurnal JESKaPe, vol. 4, no. 1 pp. 55-66, 2020.

[5] A. Ahmad and B. Sholeh, Analisis Pengendalian Persediaan Bahan Baku dengan menggunakan Metode Economic Order Quantity pada Usaha Kecil dan Menengah (UKM) Dodik Bakery, Jurnal Riset Akuntansi Terpadu, vol. 12, no. 1, pp. 96-103, 2018.

[6] N. Roswamanti and Khairullah, Optimasi Pengendalian Persediaan Bahan Baku Dengan Analisis Reorder Point, JUTISI, vol. 5, no. 3. pp. 1187-1196, 2016

[7] M. Rifandy and Marwan, Pengendalian Persediaan Bahan Baku Untuk Meningkatkan Efisiensi Biaya Persediaan UKM Wira Bag's Production dengan Mentode Economic Order Quantitiy (EOQ), IESM Journal, vol. 1, no. 2, pp. 165-173, 2019.

[8] E. Najwaini, Purnama, and N.R. Aulia, Perancangan Sistem Informasi Persediaan Barang Berbasis Web pada Alzena Hijab Store Banjarmasin, Jurnal Ilmu Komputer dan Bisnis (JIKB), vol. xi, no. 2, pp. 2473-2482, 2020.

[9] A. Junaidi and C. Sumirat, Aplikasi Persediaan Barang PT. CAD Solusindo Menggunakan Metode Waterfall, Jurnal SISFOKOM, vol. 7, no. 1, pp. 28-37, 2018

[10] J. Wijaya and I. Irwan, Sistem Informasi Pengendalian Stok Berbasis Mobile Menggunakan Metode ABC, Jurnal Mahasiswa Aplikasi Teknologi Komputer dan Informasi (JMApTeKsi), vol. 3, no. 1, pp. 20-28, 2021.

[11] R.S. Anwar, Mikhratunnisa, and T.D. Cahyono, Perancangan Aplikasi Berbasis Android dengan metode Economic Order Quantity di PT Samawa Tirta Alam Sumbawa, Jurnal Tambora, vol. 3, no. 2, pp. 49-59, 2019.

[12] W.R. Putri and I.P. Sari, Sistem Pengendalian Persediaan Bahan Baku, Inventory dan Produksi pada Home Industry Mamake dengan Metode Reorder Point Berbasis Web, Multinetics, vol. 4, no. 2, pp. 22-27, 2018

[13] A. Adrian, B. Mulyawan, M.D. Lauro, Sistem Inventori dan Penjualan Berbasis Web dan Mobile pada Roti Panggang Gadget Store, Jurnal Ilmu Komputer dan Sistem Informasi, (JIKSI), vol. 6, no. 1, pp. 1-8, 2018.

[14] H. Leidiyana and A. Anugrah, Aplikasi Pengendalian Persediaan Barang Berbasis Android dengan Metode Economic Order Quantity (EOQ) pada Bengkel Dunia Motor, Jurnal Komtika (Komputasi dan Informatika), vol. 4, no. 2, pp. 51-58, 2020.

[15] S. Tjandra and G.S. Chandra, Pemanfaatan Flutter dan Electron Framework pada Aplikasi Inventori dan Pengaturan Pengiriman Barang, Journal of Information System, Graphics, Hospitality and Technology, vol. 2, no. 2, pp. 76-81, 2020.

[16] M. Muller. Essentials of inventory management. Harper Collins Leadership, 2019.

[17] J. Heizer and B. Render. Operations management, 11 ed. Pearson Education India, 2016. 